\title{
Thermally stimulated currents studies in blends of immiscible telechelic polymers
}

\author{
J. Horrion ${ }^{1, *}$, R. Jerome', Ph. Teyssie ${ }^{1}$, J. Vanderschueren ${ }^{2}$, and M. Corapci ${ }^{2}$ \\ ${ }^{1}$ Laboratory of Macromolecular Chemistry and Organic Catalysis, University of Liege, Sart-Tilman, \\ B-4000 Liege, Belgium \\ 'Laboratory of Macromolecular Chemistry and Physical Chemistry, University of Liege, Sart-Tilman, \\ B-4000 Liege, Belgium
}

\section{SUMPARY}

Thermally stimulated polarized and depolarized currents techniques have been applied to the investigation of the morphology of blends of immiscible telechelic polymers bearing complementary functional groups. From this study,it appears that the introduction of such interacting groups produces a blend which properties are comparable with those of block copolymers.

\section{INTRODUCTION}

The design of new materials with tailored properties is nowadays usually accomplished by blending two or more polymers. As polymer mixtures quite always show phase separation and lack of interfacial adhesion, and interfacial agent,called compatibilizer or emulsifier, is added in small amounts to improve the overall properties of the blend (1).Block and graft copolymers belong to such category of products.Anyhow, even when they are used in small quantities, the cost of the resulting blend remains high because these copolymers are produced by anionic copolymerization.

To circumvent that situation,functional groups mutually interacting have been introduced onto the polymers to enhance the interfacial adhesion (2). In that respect,hydrogen bonding $(3,4)$, ion-dipole (5-7), transition metal complexes $(8,9)$ or acid-base (10-12) interactions have been successfully used to increase the compatibility between two immiscible backbones. However,because of the statistical distribution of the functional groups and the high functionality required to achieve miscibility, a comb like structure is expected to be formed between both polymers which is not suitable for their use as compatibilizer in blends of their precursors.

That undesirable situation is avoided when the interacting functional groups are located at the end of the polymer chain. Their mutual interaction provides a mean to generate some structures comparable to block copolymers (13-15). Thermal analysis, optical microscopy (14) and small angle $X$-ray scattering (15) have evidenced that the coulombic interactions resulting from the transfer of a proton between a carboxylic or sulfonic acid and an amino terminated polymers engaged the polymer chains in multiblock copolymer structures. 
To confirm the first results obtained by thermal analysis, known to be one of the less sensitive method to assess miscibility and to get a better insight into the morphology of such blends, we have used a more sophisticated method:the thermally stimulated depolarization or polarization currents techniques (TSDC and TSPC) $(16,17)$.

\section{EXPERIMENTAL}

The $\alpha, \quad \omega, \quad$ diteramino polystyrene (PS(NR2)2;Mn-13000) and the dicarboxylic acid polyisoprenes (PIP(COOH)2)2; Mn-15000, 20000, 30000, 37000,45000 ) have been prepared in T.H.F. by anionic polymerization using naphtalene sodium as a difunctinal initiator and desactivating the polyanions with 1 chloro 3 methyl propane (18) or anhydrous carbon dioxide (19). The functionality of the polymers determined by potentiometric titration of the amino or carboxylic acid end groups with p.toluene sulfonic acid and tetramethyl ammonium hydroxide in $90 / 10$ benzene-methanol mixture was about 1.95 .

Blends were prepared by solvent casting. After dissolution and mixing for two hours, the solvent was slowly evaporated and the final product dried at $110^{\circ} \mathrm{C}$ for two weeks. All the blend compositions are based on an amino to acid ratio equals to one and are summarized in Table $I$.

The TSDC and TSPC measurements were carried out on a three terminal electrode system under a controlled nitrogen flow $(25 \mathrm{~cm} 3 / \mathrm{min})$ in the dielectric cell of a relaxation spectrometer (Unirelax, Tetrahedron).

The heating and cooling rates were controlled by an automatic temperature programming system (Wizard 1501, Tetrahedron). For TSPC measurements, the sample is first cooled to $-60 \mathrm{C}$ while short circuited. An electric field $(10 \mathrm{kV} / \mathrm{cm})$ is applied and the polarization current measured during linear heating $\left(6^{\circ} \mathrm{C} / \mathrm{min}.\right)$. For TSDC experiments, the following cycle was done:(1)heating to $15^{\circ} \mathrm{C}$ and polarizing at that temperature for 10 minutes; (2) cooling in the field to $-6^{\circ} \mathrm{C}$ at a rate of $10^{\circ} \mathrm{C} / \mathrm{min}$ ), disconnected and (3) heating the short-circuited samples $\left(6^{\circ} \mathrm{C} / \mathrm{min}\right)$ and measuring the depolarized currents.

\section{RESULTS}

Figure I compares the TSPC and TSDC curves observed for PS(NR2)2 $13000 /$ PIP $(\mathrm{COOH}) 245000 / / 22 / 78$ blend. Both curves are characterized by the presence at low temperature of one peak ( $\alpha$ ) which maximum appears at about the same temperature whatever the molecular weight of the rubber (Table I).Its symmetrical shape allows the attribution of that relaxation to the glass transition temperature of the soft phase in good agreement with DSC results (14). More unexpected is the lowering of the $\mathrm{Tg}$ of the polyisoprene in the blend compared with the value found for the pure polymer $\left(-2^{\circ} \mathrm{C}\right)$. Similar observations have been reported for block copolymers poly(styrene-b-butadiene)(20) or multi-block poly (butadiene-b-aramid) (21).

This phenomena was considered has resulting from the existence of a negative pressure due to a different contraction of the two phases during cooling (20). Indeed,below the $\mathrm{Tg}$ of the hard phase, the soft polymer is always well above its $\mathrm{Tg}$ and tends to contract more,creating some voids at the interface and contributing to an increase in the free volume of the soft phase (20). 


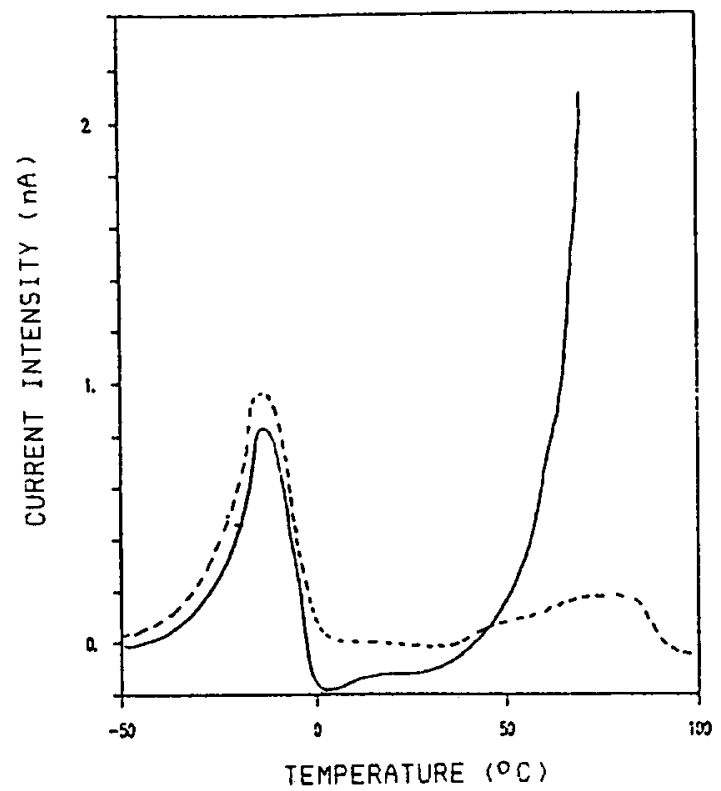

Figure I - ISDC ( (-.) and ISPC $(\longrightarrow$ curves of PIP (COOH) $245000 /$ PS $\left(\mathrm{NR}_{2}\right)_{2} 13000$ blend.

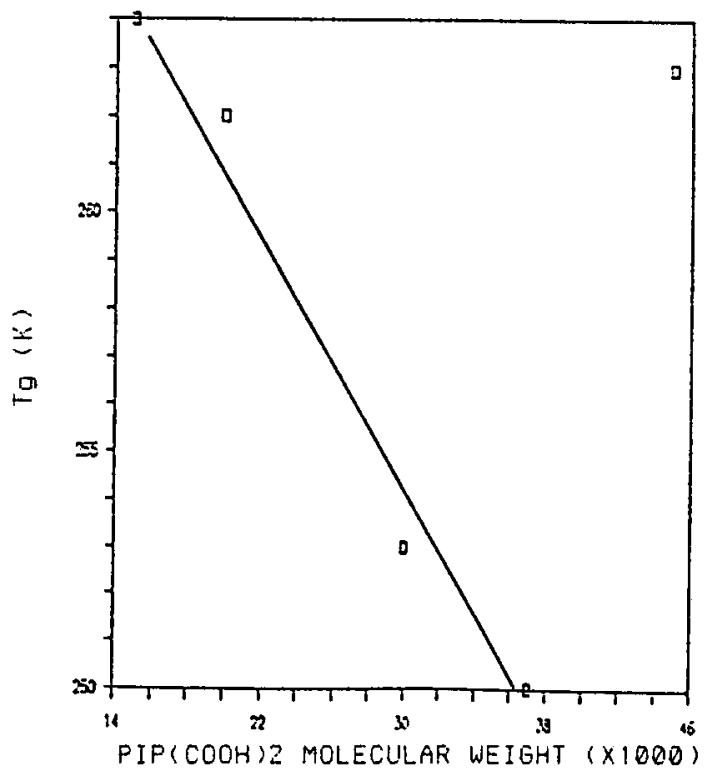

Figure II - Glass cransition temperature ( $\mathrm{g} g$ ) of the rubber phase in function of the PIP $(\mathrm{COOH})_{2}$ Molecular Weight. 


\begin{tabular}{|c|c|c|c|c|c|c|c|c|}
\hline \multicolumn{2}{|c|}{$\operatorname{PIP}(\mathrm{COOH})_{2}$} & \multicolumn{3}{|l|}{$\mathrm{Tg}_{1}\left({ }^{\circ} \mathrm{C}\right)$} & \multicolumn{3}{|c|}{$\mathrm{Tg}_{2}\left({ }^{\circ} \mathrm{C}\right)$} & $I_{m}$ \\
\hline Mn & Weight $z$ & TSPC & TSDC & $D S C(b)$ & TSPC & TSDC & $D S C^{(b)}$ & $10^{10} \mathrm{~A}$ \\
\hline 15000 & 54 & -7 & -6 & -9 & 62 & 65 & 70 & 115 \\
\hline 20000 & 61 & -16 & -16 & -11 & 60 & 66 & 66 & 85 \\
\hline 30000 & 70 & -22 & -21 & -20 & - & 66 & 58 & 18 \\
\hline 37000 & 74 & -26 & -24 & -23 & 53 & (c) & 52 & $-(c)$ \\
\hline 45000 & 78 & (a) & -11 & -10 & 57 & $-(c)$ & 52 & $-(c)$ \\
\hline
\end{tabular}

(a) no data.

(b) ref. 14.

(c) no maximum observed.

Table I - Composition and glass transition temperatures ( $\mathrm{Tg}$ ) of blends of $\alpha, \omega$ di teramino polystyrene $\left(M_{n}-13000\right)$ and $\alpha, \omega$ di carboxylic acid polyisoprenes.

In the case of poly(styrene-butadiene) block copolymers, it is the molecular weight of the soft sequence which controls the depression of $\mathrm{Tg}$ : the higher the molecular weight, the more important the depression. The same trend is observed in our blend, the only exception being the blend containing the highest molecular weight PIP( $\mathrm{COOH}) 2$ (Figure II). To explain such exception, it is worth recalling that, in blends of telechelic polymers, there is no covalent bond between the immiscible polymers so the "block copolymer" effect results from a favorable balance between the electrostatic association of the ammonium/carboxylate ion pairs and the thermodynamic tendency to phase separation. The higher the molecular weight of the telechelic polymer, the lower the amount of functional groups and the more important the forces to phase separation.

Indeed, some previous morphological observations have shown that when one diteramino polyisoprene was blended with one dicarboxylic acid poly $\alpha$ methyl styrene, incompatibility occurred when the the molecular weight of the poly methyl styrene was higher than 20000 and that its miscibility with polystyrene was better (14). With the present investigation, we can conclude that the critical molecular weight to loose the copolymerization effect is 37000 . 


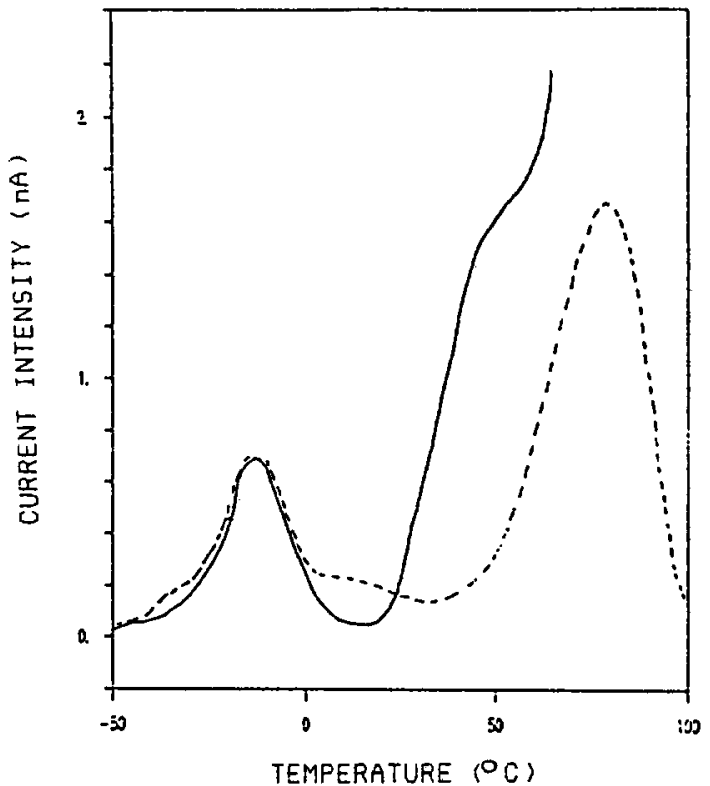

Figure III - TSDC (...) and ISPC (-) curves of PIP (COOH) $230000 /$ PS $\left(\mathrm{NR}_{2}\right)_{2} 13000$ blend.

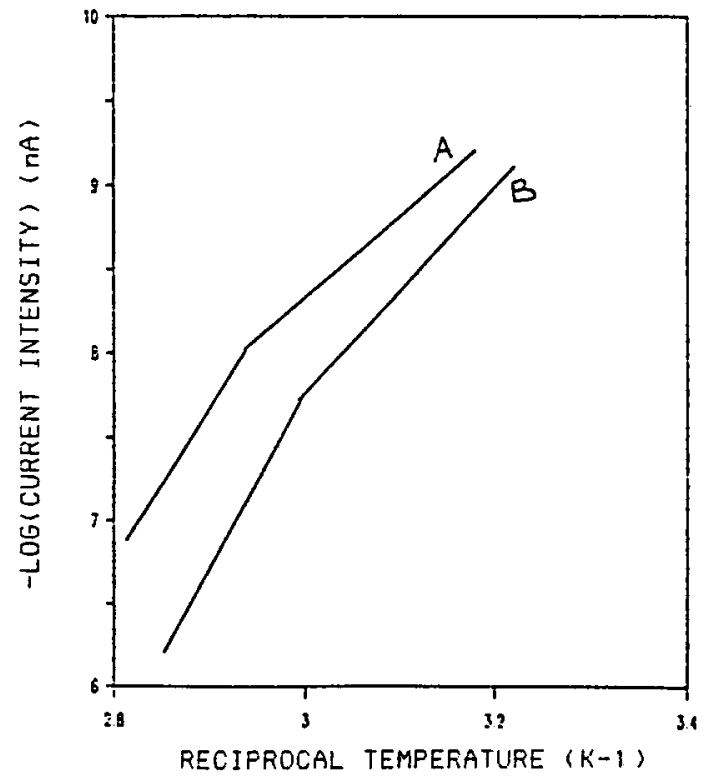

Figure IV - Plot of $-\log (\sigma)$ against reciprocal temperature for PIP $(\mathrm{COOH})_{2} 45000$ (A) and PIP $(\mathrm{COOH})_{2} 20000$ (B) based blends. 
At higher temperatures,just a small flat peak is observed in TSDC measurements (Figure $I$ ). The situation is quite different for the other blends which TSDC curves show the apparition of one new peak more symmetrical $(\beta)$ (Figure III).The temperature at which the maximum occurs is about $65^{\circ} \mathrm{C}$ whatever the blend composition whereas the intensity of the peak is related to the amount of polystyrene in the blend (Table I). The $\beta$ peak corresponds to the beginning of the conduction current observed in the TSPC curves. The origin of that peak has to be attributed to one polarization process involving charge carrier migration over macroscopic distances. So, the temperature of the maximum can not be fully attributed to the $\mathrm{Tg}$ of the polystyrene phase although the migration of charge carriers results from the softening of the rigid phase and can thus be considered as an evidence of the $\mathrm{Tg}$. This explains the differences observed between the values observed by DSC or TSDC methods (Table II).

In addition, the TSPC curve shows that the beginning of the conduction region corresponds closely to the position of the $\beta$ peak. In order to evidence the $\mathrm{Tg}$ of the polystyrene phase, the logarithm of the conductivity (-Log $\sigma$ ) has been plotted as a function of the reciprocal temperature ( $T-1$ ) (Figure IV).All the plots give a broken line which shows the presence of the two relaxation processes $: \mathrm{Tg}$ and charge migration. The temperature where the break in the curve occurs can be considered as the $\mathrm{Tg}$ (Table II). Once again, there is a difference, although smaller, between the values determined by TSPC and those observed by DSC and ISDC. Nevertheless, all these values are well below the $\mathrm{Tg}$ of the pure polystyrene and are the reflect of the block copolymer effect.

\section{CONCLUSIONS}

Thermally stimulated currents studies performed on blends of immiscible telechelic polymers have confirmed the results previously obtained by D.S.C.:a significant decrease in the $\mathrm{Tg}$ of both phases is always clearly observed whatever the molecular weight of the rubbery polymer.Beside such observations,it was found that,above a critical molecular weight for a specific polymer pair,the block copolymerization effect was no more observable because the balance of electrostatic interactions generated by the acid-base interactions and thermodynamic tendency of phase separation was in favor of the latter one.

There is no doubt that such limit is a function not only of the nature of the polymers blended together but also, and certainly to a much more important extend, to the strength of the interacting functional groups. In that respect, the evaluation of blends based on sulfonic acid replacing the carboxylic one would increase the critical molecular weight for phase separation. 


\section{REFERENCES}

1. TEYSSIE Ph.,FAYT R.,JEROME R.,Macromol.Chem., Macromol.Symp.,16,41, (1988).

2. OLABISI O.,ROBESON L.M., SHAW M.T.,"Polymer-Polymer Miscibility", Academic Press, New-York (1978).

3. PEARCE E.M., KWEI T.K.,MIN B.Y.,J.Macromol.Science, Chem. A21,1181, (1984).

4. DJADOUN S., GOLDBERG R.N., MORAWETZ H., Macromol., 10, 1015, (1977).

5. HARA M., EISENBERG A., Macromo1.,17,1335, (1984).

6. EISENBERG A., HARA M., Polym. Eng.Sci., 24, 1306, (1984).

7. RUTKOWSKA M. ,EISENBERG A., J.App1. Polym.Sci. , 33, 2833, (1987).

8. PEIFFER D.G.,AGARWAL P.K.,LUNDBERG R.D.,J.Polym.Sci., Polym.Lett. Ed. $, 24,581,(1986)$.

9. AGARWAL P.K., DUVDEVANI I,PEIFFER D.G.,LUNDBERG R.D.,J.Polym.Sci., Polym. Phys.Ed.25,839, (1987).

10. SMITH P., EISENBERG A., J.Polym.Sci., Polym.Lett.Ed. ,21, 223, (1983).

11. ZHOU Z.L., EISENBERG A.,J.Polym.Sci.,Polym.Phys.Ed. .21, 595, (1983).

12. MURAli R., EISENBERG A.,J.Polym.Sci., Polym.Phys.Ed.26,1385, (1988).

13. HORRION J., JEROME R.,TEYSSIE Ph.,J.Polym.Sci.,Polym.Lett.Ed., 24, $69,(1986)$.

14. HORRION J., JEROME R.,TEYSSIE Ph., J.Polym.Sci., Polym.Chem.Ed., submitted for publication.

15. RUSSEL T.P.,JEROME R.,CHARLIER P.,FOUCART M.,Macromo1.,21,1709, (1988).

16. VANDERSCHUEREN J.,GASIOT J., in Topics Appl.Phys.Vo137, Chap.4, Braunlich Ed.Springer Berlin, (1979).

17. VAN TURNHOUT J.,Topics Appl.Phys.Vol 33, Chap.3, Sessler Ed., Springer, Berlin, (1980).

18. BROZE G.,JEROME R., TEYSSIE Ph., Makromol. Chem., 178, 3171, (1977).

19. BROZE G.,JEROME R., TEYSSIE Ph., Macromol. 15, 920, (1982).

20. BATES F.S., COHEN R.E., ARGON A.S., Macromol., 16, 1108, (1983).

21. TAKASHI I.,SHIN-ICHI 0., KOMASA A., YOSHIO I., MacromoI.,17, 1417, (1984).

Accepted April 20, $1989 \quad$ C 